Revista Destaques Acadêmicos, Lajeado, v. 9, n. 2, 2017. ISSN 2176-3070

DOI: http://dx.doi.org/10.22410/issn.2176-3070.v9i2a2017.1215

www.univates.br/revistas

\title{
OFICINA DE MÚSICA NOS ANOS INICIAIS: CRIANDO UMA MUSICOTECA
}

\author{
Tamara Cristina Luersen ${ }^{1}$, Angélica Vier Munhoz ${ }^{2}$
}

Resumo: Este artigo é o recorte de um trabalho de conclusão do curso de Pedagogia, realizado no Centro Universitário UNIVATES, durante o período de fevereiro a novembro de 2016. Trata-se, inicialmente, de um estudo da noção de paisagem sonora em meio proposto pelo educador musical Murray Schafer. A partir de tais estudos buscou-se realizar uma oficina de música com alunos do primeiro ano de uma escola pública, localizada em Teutônia/RS, pautada na sensibilização das crianças e na utilização de materiais reutilizáveis, culminando na criação de uma musicoteca. Como o estudo envolvia a Educação Musical na escola, buscou-se também a aproximação com os documentos do Ministério da Educação acerca do ensino de música. Ao final, constatou-se que as experiências vivenciadas pelo grupo de crianças possibilitou novas formas de sentir, escutar e vivenciar os sons, criando outras paisagens sonoras.

Palavras-chave: Oficina de música. Anos Iniciais. Musicoteca.

\section{INTRODUÇÃO}

O excesso de informações é a marca da contemporaneidade. Vivemos em um mundo em que estamos vinte e quatro horas conectados em redes sociais e ferramentas de mensagens instantâneas, recebendo e compartilhando informações. Além disso, o mundo torna-se cada vez mais globalizado, de modo que recebemos as informações logo após elas ocorrerem, o que de alguma maneira pode afetar diretamente o nosso cotidiano. Assim como Bauman (2010) descreve, os nossos pais viviam em um tempo em que a comunicação era transmitida por outros meios e não era instantânea da forma como é atualmente.

Em relação à experiência com as paisagens sonoras isso não é diferente. Nesse tempo, ainda não informatizado, afirma Schafer (2001, p.99), "o trabalho costumava estar associado à canção, pois os ritmos das tarefas eram sincronizados com o ciclo de respiração humana". Com a revolução industrial,

1 Graduanda do Curso de Pedagogia do Centro Universitário UNIVATES.

2 Doutora em Educação (UFRGS) e Professora na Univates. 
a paisagem sonora conhecida pelas pessoas que trabalhavam dessa forma sofreu intensas modificações pela mudança drástica no modo que se vivia e se entendia o trabalho.

Tanto a mudança do ser humano do campo para a cidade, a partir do período da industrialização e das constantes migrações por diversos fatores, quanto as diferentes invenções humanas e a evolução da sociedade provocaram a modificação de sua dinâmica, assim como também dos seus sons através do surgimento de novas estruturas, rotinas e máquinas, como, por exemplo, a máquina de escrever, os trilhos de estrada de ferro, as rodas de ferro para carros a carvão (SCHAFER, 2001). A partir disso e por causa dessas mudanças da sociedade, a paisagem sonora, conceito criado por R. Murray Schafer, também é constantemente modificada por meio da inserção de novos elementos e modificação de muitos já existentes, o que afeta todos os que vivem neste meio.

Em relação a tantas transposições, é importante também pensar em educadores musicais que de certa forma desenvolveram suas teorias juntamente com o crescimento das grandes cidades e dos países em geral. Essa postura também é corroborada pelo Raymond Murray Schafer, que, entre o final dos anos 60 e início dos anos 70, inicia na Universidade de Simon Fraser, no Canadá, um projeto chamado "Soundscape". Dessa forma, busca-se contextualizar o termo paisagem sonora e seus elementos, como ritmo, som, silêncio, ruídos, barulhos e tudo que o sujeito, na sua subjetividade, possa perceber ouvindo.

Partindo da proposição de uma oficina de criação de instrumentos musicais, buscou-se contribuir para que uma nova paisagem sonora "surgisse" a partir da vivência da oficina, proporcionando uma educação dos sentidos e a sensibilização do ser humano em relação ao ambiente em que ele vive. Dessa forma, a importância de tal projeto foi propor uma maneira de reconfigurar a paisagem sonora das crianças de seis a sete anos, dos Anos Iniciais da Educação Básica, participantes da oficina.

Além disso, pretendeu-se aproximar da proposta pedagógica do Curso de Pedagogia do Centro Universitário UNIVATES, conforme o seu Projeto Pedagógico (2014)

[...] busca-se, ainda, um processo de aprendizagem que possibilite ao estudante interagir com suas multiplicidades e as multiplicidades do mundo, sendo sujeito desse processo, considerando que as construções de aprendizagem são resultados da ação do pensamento, dos afetos envolvidos, das experiências coletivas e das vivências singulares (p. 24).

Em outras palavras, esse trabalho está em consonância com a busca de um olhar estético, criador e sensível na formação do pedagogo. Uma educação baseada em uma produção de sentidos, por meio de experiências, encontros com as artes, reflexões e discussões, a partir da qual reavalia algumas 
verdades e, principalmente, desconstrói a existência de fórmulas prontas. Nessa perspectiva, buscou-se, no presente trabalho, encontrar algo que, para o pedagogo em formação, pudesse possibilitar novas experiências. Desenvolver um olhar especial para a educação musical, tal como ela pode ser pensada multifacetal e criativa - tornou-se assim o mote desse trabalho.

O estudo partiu de uma pesquisa por meio de livros, artigos, recortes, vídeos, sons, filmes, músicas, conversas, ruídos, barulhos, conceitos, silêncio, timbre, amplitude, melodia, textura, ritmo, entre outros, cujo objetivo era fundamentar a compreensão do conceito de paisagem sonora. $\mathrm{O}$ trabalho teve como modo de abordagem a pesquisa qualitativa de natureza exploratória, buscando a investigação de percepções, valores por meio da proposição da oficina de criação de instrumentos musicais. A paisagem sonora, a partir de Raymond Murray Schafer, foi central para esta proposição das oficinas de música para a criação de instrumentos musicais.

O estudo, assim como a oficina, foi realizado em uma Escola Pública localizada em Teutônia/RS. A oficina foi realizada com crianças do primeiro ano dos Anos Iniciais, no turno da manhã.

Cabe destacar que a noção de oficina aqui é tomada a partir da perspectiva de Correa (2011), o qual traça a oficina como uma prática potente e diferenciada, podendo provocar rupturas no currículo formal. Conforme Corrêa (2011, p. 197), “...A oficina inicia quando se quer conhecer algo", ou seja, não está pré-determinado pelo currículo nacional, por uma lista de conteúdos ou por um plano organizado a priori.

\section{NOTAS (MUSICAIS) TEÓRICAS}

O referente estudo serviu de partida para o desenvolvimento de uma oficina de música para a criação de instrumentos musicais, realizada com o primeiro ano dos Anos Iniciais da Educação Básica. Para tanto, foi necessário entender a visão teórica de como se vê uma oficina pedagógica de música, os documentos do Ministério da Educação específicos relativos à Educação Musical no Brasil e a mudança na organização do início do Ensino Fundamental nas escolas.

No Brasil, existem oficialmente o Referencial Curricular Nacional para a Educação Infantil (1998) e os Parâmetros Curriculares Nacionais (1997) para $1^{\mathrm{a}}$ a $4^{\mathrm{a}}$ série do Ensino Fundamental. Dois documentos que, de forma específica, tratam sobre o ensino de Música. Desde o ano da publicação destes dois documentos, aconteceram mudanças no cenário educacional quanto à organização da transição da Educação Infantil para os Anos Iniciais. O Ensino Fundamental passa a ser chamado de Anos Iniciais e a sua faixa etária é reorganizada da mesma forma. Justamente por essas mudanças - ou seja, pela resolução que define o ingresso da criança no primeiro ano dos Anos Iniciais com seis anos - os dois documentos não são atuais. 
A desatualização deve-se à implantação do Ensino Fundamental que de oito vai para nove anos. Conforme a Lei 11.274, art. 32, de 2006, a duração do ensino fundamental, de forma gratuita na escola pública, inicia-se aos seis anos e tem como objetivo,

[...] I - o desenvolvimento da capacidade de aprender, tendo como meios básicos o pleno domínio da leitura, da escrita e do cálculo; II - a compreensão do ambiente natural e social, do sistema político, da tecnologia, das artes e dos valores em que se fundamenta a sociedade; III - o desenvolvimento da capacidade de aprendizagem, tendo em vista a aquisição de conhecimentos e habilidades e a formação de atitudes e valores; IV - o fortalecimento dos vínculos de família, dos laços de solidariedade humana e de tolerância recíproca em que se assenta a vida social. (documento digital)

A discussão sobre a ampliação do Ensino Fundamental teve início em 2004 e passou a vigorar em 2005. Segundo o site do Ministério da Educação, em seu documento de apresentação do Ensino Fundamental de nove anos ${ }^{3}$, prevê-se que as escolas de Educação Básica do Brasil têm até 2020 para a sua implantação.

Contudo, mesmo que o Ensino Fundamental de nove anos vigore desde 2005, não há nenhum referencial que contemple a disciplina de Educação Musical a partir deste ano. Somente a partir de 2008, com a Lei 11.769/2008, é implementada a obrigatoriedade do ensino da Música na Educação Básica. A partir dessa lei, a música deveria ser conteúdo obrigatório, mas não exclusivo do componente curricular e os professores e as escolas deveriam se preparar para ensinar música a partir de 2011.

Anterior a isso, a Lei 5.692/1971 ${ }^{4}$ introduziu, sob a denominação de "Educação Artística", a ideia de uma área como atividade complementar de outras disciplinas do currículo. Posteriormente, com a LDB no 9.394/1996, houve nova modificação e a Educação Artística passou a ser denominada de Artes, constituindo-se como um componente curricular obrigatório da Educação Básica.

Em 1997, a propagação dos Parâmetros Curriculares inclui um documento voltado para o Ensino de Arte, contemplando as diferentes linguagens: Teatro, Artes Visuais, Dança e Música. A partir daí também surge a criação de cursos especializados para formar professores em cada uma das linguagens e não mais um curso de Educação Artística multidisciplinar.

3 Disponível em: <http://portal.mec.gov.br/ensino-fundamental-de-nove-anos>.

4 Disponível em: <http://www2.camara.leg.br/legin/fed/lei/1970-1979/lei-5692-11-agosto1971-357752-publicacaooriginal-1-pl.html>. 
A discussão da Base Nacional Comum Curricular, iniciada em 2015 e ainda não homologada, coloca a arte como parte importante do currículo, cujo objetivo é incentivar o senso crítico, o exercício de autoria e o trabalho em grupo. Além do mais, conforme a $\mathrm{BNCC}$,, os conteúdos trabalhados no ensino de Artes não devem ser vista como adorno nos currículos ou somente voltados para datas comemorativas, entretenimentos, mas como "um conhecimento organizado e sistemático, que propicia aos estudantes a criação e recriação de saberes artísticos e culturais" (BRASIL, 2016, p. 232). O ensino de música, como uma das linguagens integrantes da área de Artes, pode ser pensada, portanto, a partir dessas diretrizes.

Os estudos com a Base Nacional Comum Curricular nos ajudaram a nortear e definir a área de arte e a sua importância no currículo. Assim, a partir dessa breve trajetória dos documentos nacionais, acerca do ensino da arte e da música, foi pensada a oficina de música, proposta para um grupo de crianças entre seis e sete anos, faixa etária atual de $1^{\circ}$ Ano dos Anos Iniciais, de uma escola pública do município de Teutônia/RS, em outubro de 2016.

Nessa prática denominada oficina de música, aplica-se o desenvolvimento de uma ação com o intuito de provocar um estranhamento no qual o sujeito participante sinta-se à vontade para criar e aprender. Em uma oficina, é importante também que quando os participantes são crianças, de forma autônoma, sejam protagonistas de suas aprendizagens. Dessa forma, em qualquer oficina pedagógica sempre há a presença de um professor responsável pelo(s) encontro(s) a fim de orientar a prática.

Nesse sentido, a oficina de música acontece como forma de estudar ou desenvolver algo dentro da área da música independentemente de quantos encontros sejam promovidos. Assim, para tal oficina, dispõe-se de um objetivo pedagógico específico quanto ao que se deve aprender, sendo que a prática realizada na mesma é embasada em referenciais teóricos, citados anteriormente.

$\mathrm{Na}$ oficina proposta, tais atitudes e conceitos para com a formação musical da criança foram introduzidas a partir da musicoteca. A escolha do nome é uma forma de brincar com a sonoridade das palavras criando um neologismo para designar o conjunto de práticas da oficina de música do projeto. A palavra é uma junção do início da palavra música com o sufixo -teca. A origem do sufixo, conforme o Dicionário Priberam Online ${ }^{5}$, é do latim theca, significa uma caixa, estojo, ou seja, um lugar para armazenar coisas.

5 Disponível em: <http://www.priberam.pt/dlpo/-teca>. 
Além disso, a vida e obra de R. Murray Schafer ${ }^{6}$ e o conceito de paisagem sonora, por ele criado, nos auxilia a entender de que maneira a música assume importância no contexto em que vivemos e em como podemos compreendê-la de diversas outras maneiras que até então foi conhecida.

$\mathrm{O}$ conceito de paisagem sonora parte de uma inquietação quanto ao aumento de ruídos na cidade em que viveu. Para Schafer (2001), o objetivo era mostrar de que modo a paisagem sonora havia evoluído no decorrer da história, como ela é dinâmica e também poderia se transformar.

Schafer (2001, p. 23) nos apresenta "a paisagem sonora como sendo qualquer campo de ambiente acústico". Entende-se que a paisagem sonora é o que o sujeito, dentro de sua subjetividade, ouve no seu cotidiano ou nos diferentes espaços que perpassa em sua vida. Da mesma forma, mesmo que este esteja ao lado de outras pessoas, não serão ouvidos os mesmos elementos sonoros neste ambiente acústico. Segundo o autor, isso se deve ao fato de que não damos total atenção a todos os ruídos e barulhos que não sejam considerados bons ou interessantes aos nossos ouvidos. Contudo, para Schafer (2010) a paisagem sonora tem se modificado de maneira rápida e o autor se ocupa em avaliar de que modo essas mudanças que ocorrem, podem estar afetando o nosso comportamento e a nossa escuta.

Assim, para tal cuidado com o meio ambiente, torna-se necessária uma reflexão de nosso comportamento, assumindo a postura de sujeito ecológico preocupado com as mudanças que vem acontecendo no mundo em que vivemos. É perceptível que seja necessário um estudo da ecologia acústica ${ }^{7}$ e da paisagem sonora para que o sujeito tenha um panorama do meio ambiente em que se vive e as transformações nesse meio.

Conforme Carvalho (2012),

Em sua condição de modelo ideal, é, pois, importante compreender quais são os valores e crenças centrais que constituem o sujeito ecológico e como ele opera como uma orientação de vida, expressando-se de diferentes maneiras por meio das características pessoais e coletivas de indivíduos e grupos em suas condições sóciohistóricas de existência. $\mathrm{O}$ sujeito ecológico agrega uma série de traços, valores e crenças e poderia ser descrito em facetas variadas. (p. 67)

6 Segundo Mateiro e Ilari (2012), R. Murray Schafer, nasceu em 1933, no Canadá. Permanece no país até por volta de 1956, onde iniciou sua formação. Passa um período de seis anos na Europa e quando retorna é contratado pela Universidade de Simon Frasen onde inicia seu curso "Limpeza de ouvidos". Além disso, publica seu estudo em cinco livros sobre Educação Musical, reuniu todos em uma única publicação chamada O ouvido pensante (1991). Como resultado da pesquisa, publicou o livro Afinação do Mundo (2001).

7 A ecologia acústica trata do estudo do sujeito com o meio em que ele vive. 
Desse modo, é necessário formar sujeitos e dar exemplo aos mesmos para que entendam que dentro do seu meio é possível modificar pequenas ações e atitudes até que as mesmas se tornem grandes. Nessa medida, percebese que a compreensão da paisagem sonora em meio à relação com o sujeito ecológico nos auxilia a buscar outras percepções do meio ambiente em que estamos inseridos.

\section{MUSICOTECA}

Eé a partir da conceitualização do que se entende por oficina que partimos para a proposta de criação de uma Musicoteca, nome criado especialmente para ser usado na oficina de criação de instrumentos musicais aqui proposta. Assim, entende-se por Musicoteca, os sons e instrumentos criados e as percepções das crianças participantes da oficina.

Além disso, é importante ressaltar que foi proposto o envolvimento direto das crianças participantes na criação e construção de instrumentos musicais, o que traz um caráter pedagógico muito especial a essa proposta. Além disso, a Musicoteca tem outro espaço e tempo, especialmente o espaço que, de uma forma é algo concreto, mas de outra, parte da invenção de quem o habita. Pensando ou agindo, a Musicoteca existe. A Musicoteca tem a potencialidade de reunir diversas práticas e quem delas participa acaba sendo sensibilizado para outras atividades e experimentações. Assim, passo a discorrer sobre as práticas realizadas na oficina que faz parte da Musicoteca.

Em nosso primeiro encontro, foi proposto às crianças que caminhassem pelo pátio da escola e encontrassem objetos e coisas que fizessem sons. Quando retornaram, propus que seus nomes fossem ditos e que utilizassem este objetivo para auxiliá-las. De maneira bem curiosa, a maioria das crianças tocou seus objetos da mesma maneira que as sílabas são separadas no seu nome. Em seguida, solicitei que as crianças caminhassem pela escola e que ao final da caminhada fossem para a sala. Ainda, em uma conversa bem interessante sobre o que haviam ouvido, sua percepção, atenção e descoberta sobre os sons, ou melhor, barulhos (como as mesmas disseram) ocorreu neste primeiro dia. Depois de socializarmos as experiências, explorei a escrita das crianças solicitando que escrevessem o que haviam escutado.

No segundo encontro, iniciamos com a leitura do livro "Barulho, Barulinho, Barulhão" (2004) de Arthur Nestrovski. A contação da história iniciou-se de forma silenciosa pelas crianças, mas o que eu não havia dito a elas é que logo mais estariam fazendo os sons de cada barulho, citado pelo livro. Além disso, solicitei que relatassem outros sons que pudessem perceber ou ter ouvido. No trecho, "Barulhos da barriga", eu indaguei sobre quais poderiam ser esses barulhos. Prontamente, uma das crianças citou "fome" e a segunda "Quando se toma água e daí se balança a barriga assim e se tem água", entre outros comentários e percepções da parte deles. 
Para o nosso terceiro encontro, foi proposto às crianças que desenhassem os barulhos que conheciam. De certa maneira, que pudessem expandir suas percepções a ponto de lembrar ou saber quais os sons que ouviam em sua rotina. Dentre os desenhos foram destacados os seguintes barulhos: bandas com vários instrumentos, gaitas, mesas e portas para bater, caminhão de lixo, carro de som, ônibus, flauta doce, sorvete, reco-reco, palmas, pratos no refeitório e em casa, a bola quicando, a mulher vermelha de tanto gritar com o fantasma, a árvore e dedos batendo nas mãos. Destes desenhos foi confeccionado um livro "Musicoteca/Sinais de fumaça 1,2,3/ Barulhos".

Em nosso quarto encontro, iniciamos a organização para a criação dos nossos instrumentos musicais. Primeiramente, brinquei com alguns sons que estavam na sala pedindo que as crianças ficassem com os olhos fechados e os escutassem. Em seguida, as crianças puderam pegar os objetos do primeiro encontro ou buscar outros que acreditavam serem importantes.

No nosso último encontro, tivemos o auxílio das crianças do Segundo Ano dos Anos Iniciais. Na sala, nos organizamos em grupos para que as crianças do Primeiro Ano pudessem ter algum auxílio maior. Solicitei então que as crianças do Segundo Ano auxiliassem na criação dos instrumentos e deixei livre para que pudessem criar os seus também. Com as crianças organizadas dessa forma, deixei as mesmas livres com vários materiais pela sala, principalmente aqueles objetos que tinham selecionado como caixas de cereal, caixas de leite, garrafa pet, caixa de ovos, fita durex, cola, tesoura, E.V.A, guizos e barbante. Dentre tantas falas ditas pelas crianças há uma que não consigo esquecer. Enquanto colávamos alguns instrumentos com fita durex, umas das crianças que estava observando disse "Ó, a fita também tem barulho!". Enfim, foram vários materiais utilizados para confecção dos instrumentos musicais que podem ser conferidos no livro confeccionado por nós chamado "Musicoteca/ Sinais de fumaça 1,2,3/Que som é esse?".

Para finalizarmos as manhãs de trabalho, nos sentamos em uma parte da escola para mostrarmos aos demais participantes da oficina e para algumas professoras o que havia sido produzido. Cada criança teve a oportunidade de contar sobre seus instrumentos. Percebi que todos foram feitos com muita atenção por parte de cada criança. Vários nomes engraçados surgiram para os instrumentos. Enquanto eu assistia e escutava, dois nomes chamaram-me mais atenção. Uma das crianças acabou criando dois instrumentos, o primeiro instrumento com várias latas, caixa, um pedaço de pauzinho de árvore, todo colorido foi nomeado "Sininho topete". O outro foi construído a partir de um pedaço de caixa de leite e algumas britas dentro dele, assim que tocado questionei sobre o nome do instrumento e a mesma disse "Humm,é... brita... é Brita brita"

A partir desse olhar destaca-se que todas as atividades aqui descritas partiram de uma intencionalidade. Acredito que nem todos os materiais, principalmente os do pátio, foram encontrados tão rapidamente. Não há como 
prever o que as crianças acreditaram ter som ou não, por isso, a intenção foi deixá-las encontrar, separar e nós nos questionarmos juntos sobre os materiais dispostos. É claro que as coisas que encontramos ou os materiais na Escola não foram suficientes, mas criamos e buscamos possibilidades junto com os materiais alternativos.

Sendo assim, cada atividade, a partir do planejamento, teve por princípio a flexibilidade, de poder "mover-se" de lugar ou momento, de modo que somente a construção dos instrumentos musicais deveria ficar sob minha responsabilidade. Além disso, todas as atividades foram planejadas, mas foi importante partir da compreensão e principalmente da espera de entender que os participantes da oficina buscariam materiais que os mesmos acreditassem serem importantes ou que produziam barulho. Além disso, neste processo, em alguns momentos foi preciso que as crianças fossem questionadas, como "Você tem certeza que é isso?"; "Se eu passar a mão aqui, ou bater não há um som também?". Foi algo bem experimental, mas com potência para acontecimentos e descobertas.

Ressalto que foi uma semana de encontros, na qual o que se buscou como objetivo não foi propriamente um resultado final único, uma vez que essas experiências vividas poderão ecoar em outros momentos futuros da vida dos participantes da oficina.

Eis aí, talvez, o propósito desta proposta: a experimentação de uma Musicoteca.

\section{CONSIDERAÇÕES FINAIS}

Desde o início do estudo acreditei que o tema escolhido - paisagem sonora e a criação musical - de certa forma compunham aquilo que vivemos atualmente. $\mathrm{O}$ estudo vinha ao encontro de uma necessidade minha, resultante da minha experiência com a música, mas também da percepção de um mundo que não escuta mais ou somente escuta sons automatizados. Verificar com autores, afinal dois são citados e parece que somente uma fez efetivamente o trabalho...

O conjunto de práticas realizadas com as crianças, em forma de oficina, foi muito significativa, pois pôde contribuir com uma educação dos sentidos na medida em que foram oferecidas formas de sentir, escutar, vivenciar os sons, quando foi dada a possibilidade de criação de algo que inicialmente não havia sido experimentado por esse grupo de crianças. Atualmente, em um contexto onde existem muitas tecnologias eletrônicas não nos parece uma prática cotidiana a de criação, percepção e escuta.

A Musicoteca é um dos tantos exemplos de criação que podem existir em escolas e acredito que foi esse um dos principais objetivos que, mesmo não traçado no estudo inicial, esteve presente em todo o processo. 
Da mesma forma, acredito que a aproximação com o referencial teórico de Schafer, possibilitou dar suporte às diversas situações propostas, nas quais a sensibilidade, a escuta e as percepções encontraram espaço, oportunizando processos de criação. Percebeu-se também que durante o andamento das oficinas é de suma importância levar em conta o contexto na qual os participantes estão inseridos. E nesse trabalho foi possível que tal contextualização ocorresse.

Por fim, acreditar na potência que existe entre a Pedagogia e a Educação Musical foi algo que busquei durante todo o processo de formação. Alinhar essas duas áreas, propondo atividades e reflexões, foi uma das surpresas mais bonitas que um final de curso de Pedagogia poderia ter me possibilitado.

\section{REFERÊNCIAS}

BAUMAN, Zygmund. 44 cartas do mundo líquido moderno. Tradução: Vera Pereira. Rio de Janeiro: Editora Zahar, edição eletrônica: Julho 2011.

BRASIL. Base Nacional Comum Curricular. $2^{\circ}$ versão revisada, Ministério da Educação, 2016. Disponível em: http:/ /basenacionalcomum.mec.gov.br/ documentos/bncc-2versao.revista.pdf. Acessado em: 04/12/2016

BRASIL. Lei de Diretrizes e Bases da Educação no 9.394, de 20 de dezembro de 1996, art. 32. Disponível em: http://portal.mec.gov.br/seesp/arquivos/pdf/lei9394_ldbn1. pdf . Acessado em 10/12/2016

BRASIL. Lei no 11.274, de 6 de fevereiro de 2006, Art.32. Disponível em: http:/ / www.planalto.gov.br/ccivil_03/_ato2004-2006/2006/lei/111274.htm. Acessado em: $04 / 12 / 2016$.

BRASIL. Lei n ${ }^{\circ}$ 5.692, de 11 de agosto de 1971, Art. 7. Disponível em: http:/ / www2.camara.leg.br/legin/fed/lei/1970-1979/lei-5692-11-agosto-1971-357752publicacaooriginal-1-pl.html . Acessado em: 10/12/2016

BRASIL. Lei no 9.394, de 20 de dezembro de 1996. Art. 32. Disponível em: https:/ / www.planalto.gov.br/ccivil_03/LEIS/L9394.htm\#art32. Acessado em: 15/05/2016

BRASIL. Parâmetros Curriculares Nacionais: Artes. Secretaria de Ensino Fundamental. Ministério da Educação. Brasília: MEC/SEF, 1997. Disponível em: http://portal.mec.gov.br/seb/arquivos/pdf/livro06.pdf

CARVALHO, Isabel Cristina de Moura. Educação Ambiental a formação do sujeito ecológico. Ed. 6. São Paulo: Cortez. 2012.

CENTRO UNIVERSITÁRIO UNIVATES. Projeto Pedagógico Curso Pedagogia, Licenciaturas. 2014. 
CORRÊA, Guilherme Carlos. PREVE, Ana Maria Hoepers. A Educação e a Maquinaria escolar: produção de subjetividades, biopolíticas e fugas. REU, Sorocaba, SP, v. 37, n.2, p. 181-202, dez. 2011.

DICIONÁRIO PRIBERAM DA LÍNGUA PORTUGUESA. “-teca”, 2008-2013, http:/ / www.priberam.pt/dlpo/ . Acessado em: 16/05/2016.

ENTREVISTA R. Murray Schafer, La semanine du Son 2010. Paris. Disponível em: $<$ https:/ / www.youtube.com/watch?v=-YEAEBSiBYA>. Acessado em: 15/05/2016.

MATEIRO, Teresa. ILARI, Beatriz (org.). Pedagogias em Educação Musical. [livro eletrônico]. Curitiba: Editora Intersaberes, 2012.

NESTROVSKI, Arthur. Barulho, Barulinho, Barulhão. São Paulo: Cosac Naify, 2004. Ed.1.

SCHAFER, R. Murray. Educação Sonora: 100 exercícios de escuta e criação de sons. Tradução Marisa Fonterrada. - São Paulo: Editora Melhoramentos, 2009.

SCHAFER, R. Murray. A afinação do mundo. Tradução Marisa Trench Fonterrada. São Paulo: Editora UNESP, 2001. 